\title{
LA IDENTIDAD EN JUEGO: UN ACERCAMIENTO AUTOFICCIONAL A LA CASA EN MANGO STREET
}

The identity at stake: an autofictional approach to The House on Mango Street

\author{
LAURA $\mathrm{M}^{\mathrm{a}}$ MONTES ROMERA ${ }^{1}$ \\ UNIVERSIDAD DE GRANADA (ESPAÑA) \\ lauramonro@ugr.es // orcid.org/0000-0001-9934-0192
}

RECIBIDO: 30 DE ABRIL DE 2020

ACEPTADO: 8 DE SEPTIEMBRE DE 2020

RESUMEN: Este artículo explica la construcción autoficcional de La casa en Mango Street, obra de la chicana Sandra Cisneros. Parte de la base teórica que considera la autoficción como un género no subordinado a otros, siguiendo la posición de Vera Toro, y elabora un estudio de las claves poéticas de la obra, así como de las condiciones sociohistóricas en que ha sido escrita. Analiza también cómo es el espacio el elemento narrativo fundamental que permite establecer una relación entre la creación literaria, la creación de identidad del pueblo chicano y la de la mujer-narradora de la obra. En este estudio no perdemos tampoco de vista el fuerte carácter crítico del texto: por un lado, observaremos la identidad en su colectividad chicana, atendiendo a ese espacio dinámico e híbrido o espacio intersticial, tal y como lo conceptualiza Homi Bhabha. Por otro lado, veremos esa identidad enunciada desde un sujeto-alteridad femenino, o más bien desde unas alteridades femeninas, poniendo en diálogo ese lugar intermedio con el de la paradójica wild zone que supone la narración de Esperanza Cordero.

PAlabras ClaVE: La casa en Mango Street, autoficción, literatura chicana, identidad, espacio, alteridad, wild zone, poética.

ABSTRACT: This article explains the autofictional construction of The House on Mango Street, literary work of the Chicana Sandra Cisneros. It is based on the theoretical basis that considers autofiction as a genre not subordinated to others, following the position of Vera Toro. It elaborates a study of the key elements of the poetic work, as well as the sociohistorical conditions in which it got written. It also analyzes how space is the fundamental narrative element that allows us to establish a relationship between literary creation, the creation of the identity of the Chicano people and the female narrator from the piece. In this study we are also taking into account the text's strong critical character: on one side, we observe the Chicana identity at a community level, meeting this dynamic and hybrid or interstitial space, as Homi Bhabha conceptualizes it. On the other side, we see this identity enunciated from a feminine subject / alterity point of view or even from let's say feminine alterities, bringing into dialogue this intermediary place with the paradoxical wild qone that entails Esperanza Cordero's narration.

KEYwORDS: The House on Mango Street, autofiction, Chicana literature, identity, space, alterity, wild zone, poetic.

${ }^{1}$ Becaria FPU en el Departamento de Literatura Española de la Facultad de Filosofía y Letras, Universidad de Granada. 
La escritora chicana Sandra Cisneros da voz en La casa en Mango Street (1984) a una niña preadolescente que, como ella, vive su infancia en un barrio cualquiera de la ciudad de Chicago. En uno de los primeros episodios, Esperanza reflexiona sobre el origen de su nombre, que ella hereda de su abuela mexicana, y sobre la significación que ese nombre guarda para ella: "In English my name means hope. In Spanish it means too many letters. It means sadness, it means waiting" (10). Además de establecerse ya una barrera entre la Esperanza "angloamericana" y la Esperanza "mexicana" 2, si avanzamos un poco más en el episodio nos encontramos con el siguiente desafío:

I would like to baptize myself under a new name ${ }^{3}$, a name more like the real me, the one nobody sees. Esperanza as Lisandra or Maritza or Zeze the X. Yes. Something like Zeze the X will do (11).

Como vemos, nuestra narradora parece aquí por un momento otorgarle la palabra a la propia Sandra Cisneros para confesar que bajo el nombre de Esperanza se esconden muchos otros nombres, muchas otras identidades; en definitiva, muchos otros yoes.

La obra de Sandra Cisneros permite visualizar y explicar esos yoes limítrofes, movedizos, e incluso, en algunos casos, contradictorios entre sí. Para poder hacerlo, hemos de considerar la autoficción como un género literario independiente o no subordinado al de la autobiografía, teniendo en cuenta y superando los análisis previos de Lejeune del género autobiográfico y de Alberca de la autoficción como un género ambiguo e híbrido.

Seguimos, asimismo, la reciente perspectiva de Vera Toro y también su metodología poética, mediante la cual se observa que la construcción de la autoficción en el texto se va haciendo con mecanismos metaficcionales y autorreflexivos. Además, el espacio, y no el tiempo, se constituye como un elemento narrativo que posibilita la autoficción en La casa en Mango Street, la obra que ocupa nuestro análisis teórico y poético, tanto por su referencialidad a la identidad del pueblo chicano como a la búsqueda de la realización femenina en un sistema fuertemente opresor. Con este objetivo ubicaremos la obra tanto literaria como sociohistóricamente, así como la estudiaremos en términos de espacialidad y horizontalidad. Encontramos, desde estos planteamientos, una posibilidad de diálogo entre los conceptos de wild zone, propuesto por Edwin y Shirley Ardener; borderland, desde Gloria Anzaldúa; y cultura intersticial, a partir de Homi K. Bhabha. Todo ello desde un estudio de las poéticas de la obra de Cisneros.

\footnotetext{
2 Esperanza constantemente a lo largo de la obra hará referencias a sus raíces mexicanas (a la lengua hispana en que ella piensa determinadas realidades o hace concretas asociaciones), y a sus vivencias norteamericanas, tal y como la propia Sandra Cisneros ha observado de sí misma: "when she thinks to herself in her father's language, she knows sons and daughters don't leave their parents' house until they marry. When she thinks in English, she knows she should've been on her own since eighteen" (xiii).

Curiosamente, tanto Sandra como Esperanza asocian el inglés, la lengua de la cultura dominante y mayoritaria en EEUU, a la libertad o al empoderamiento como mujeres. La asocian a la posibilidad de crear y construir una identidad propia, pero, como veremos, siempre entre dos bordes o fronteras no muy definidas.

${ }^{3}$ Las cursivas que aparecen en los diferentes pasajes son de la autora de este artículo.
} 


\section{¿UNA AUTOFICCIÓN?}

En La casa en Mango Street tanto los espacios realmente existentes escogidos por Cisneros para desarrollar la(s) historia(s) 4 (los barrios en las periferias de la ciudad de Chicago; Loomis, Keeler o Paulina), como los propios acontecimientos de la vida de Esperanza en un barrio marginal hacen que los lectores establezcamos en seguida unos lazos de identidad entre la escritora y la narradora-protagonista 5 .

En ese sentido, y partiendo de las reflexiones de Esperanza acerca de su propio nombre, la "credulidad" que el lector debe depositar sobre la narración autobiográfica se deshace al leer La casa en Mango Street, pues en la autobiografía el lector es consciente de que la mímesis absoluta de la realidad de las experiencias del autor es difícil o imposible de mantener a lo largo de todo el relato $^{6}$. En cambio, en un texto fronterizo como el que nos ocupa, la historia se nos presenta desde el principio como verosímil pero no necesariamente veraz; nos libera del compromiso rígido con lo real, impuesto por la autobiografía, y nos permite bucear en la elástica ambigüedad de la novela, en sus mecanismos de creación de referencialidad, mediante la imaginación de la escritora chicana Sandra Cisneros.

Los lazos de identidad que el lector establece entre persona-personaje, esas vacilaciones, son los que hacen que la obra se tambalee entre dos géneros literarios bien diferenciados por la crítica tradicional: la autobiografía y la novela personal. Alberca considera este discurso como una "excepción o desvío de las reglas, una tierra de nadie entre el pacto autobiográfico y el novelesco" (Alberca, 2007:64). Sin embargo, tanto considerar la autoficción como un texto híbrido entre ambos géneros (como hace Alberca), como considerarla la expresión autobiográfica del yo posmoderno o contemporáneo son reflexiones que no ponen tanto de relieve el énfasis que la autoficción hace de su carácter ficticio. Impiden, de hecho, colocarla en un nivel de estudio no subordinado, sino paralelo al de los géneros anteriores (Toro, 2017: 22).

Esta presión de la veracidad autobiográfica, por otra parte, acercaría más la obra a un estilo prosaico y referencial, basado fundamentalmente en la narración de una vida en el tiempo "con

\footnotetext{
${ }^{4}$ Como veremos, aunque La casa en Mango Street podría parecer un diario íntimo en el que se narran episodios sueltos en el día a día de Esperanza (sin fecha concreta), la mayor parte de las "viñetas", tal y como Sandra Cisneros llama a los capítulos en el prólogo, giran en torno a otros personajes secundarios, que de hecho no siempre vuelven a aparecer en el resto de la obra.

5 Si bien esos lazos no nos hacen hablar de un "pacto autobiográfico", pues asumimos desde el principio que autora y narradora-protagonista no coinciden, sí podríamos afirmar que, en ese juego de referencialidades entre Sandra y Esperanza, persona y personaje se confunden hasta confundir también realidad y ficción.

${ }^{6}$ Recordemos, brevemente, que los estudios autobiográficos se han sustentado en el nombre propio como garantía de correspondencia absoluta entre autor y narrador, o lo que es lo mismo, entre vida (experiencia) y obra (discurso). Así, para Lejeune, "queda excluida por definición la coexistencia de la identidad del nombre y el pacto novelesco, y la posibilidad de que se dé un nombre diferente y un pacto autobiográfico" (Lejeune, 1975: 66), y esto ocurre aunque "la historia sea presentada como ficticia (y tomada por verdadera por el lector, quien la relaciona con el autor)" (1975: 67).

Conviene mencionar, para comprender los enfoques posteriores de los estudios autoficcionales, que el cuestionamiento del concepto clásico de "autor", y sus aparejados matices de "sinceridad" y "fiabilidad" en el discurso, se viene haciendo desde los años 60 y 70, cuando ya Barthes afirmaba que la escritura es "un lugar neutro" donde la voz pierde toda identidad, "comenzando por la propia identidad del cuerpo que escribe" (1967: 65). O cuando Foucault integra la noción de "autor" en la interpretación de las obras como una función más en la red de relaciones intra-textual, proponiendo la fragmentación del sujeto en varios egos, varias identidades, que conviven simultáneamente junto con el resto de elementos del relato (1969: 12).
} 
una perspectiva fundamentalmente retrospectiva" (Lejeune, 1975: 51). Pero, por el contrario, en este artículo defendemos que La casa en Mango Street fluye más lírica y metafóricamente al contar una vida en el espacio. El texto no presenta el que podría considerarse uno de los rasgos fundamentales de un diario íntimo, esto es, la fecha exacta del día en que se escribe cada fragmento o viñeta. De hecho, como veremos, es precisamente la carencia de protagonismo de la temporalidad de los hechos lo que nos permite argumentar que es el espacio el elemento que posibilita la narración de la vida de Esperanza. Sin embargo, esa estética breve, concentrada, casi pictórica, que iremos aquí esclareciendo, dialoga constantemente con un ritmo latente en el relato que conduce a la voz narrativa, poco a poco, a su maduración o adultez. En este sentido, se trataría de una especie de "coming-of-age" que culmina con una reflexión sobre el lugar y la identidad en los que se sitúa la voz narrativa, y es en este punto, así como en otros que iremos anotando, donde vinculamos la obra al género diarístico, sin tratarse puramente de un diario.

La mayor parte de las lecturas de la obra de Cisneros la caracterizan, de hecho, por su falta de "pureza". En primer lugar, a nivel textual la obra deambula entre el terreno de la novela, el de la autobiografía y el del conjunto de relatos cortos o "short story cycle"7. Al mismo tiempo, y como veremos, su prosa está impregnada de recursos que la aproximan al género de la poesía.

Lo que aquí defendemos es, pues, que se trata de un texto autoficcional, lo cual abraza la reflexión de Claire Smith de que la obra cae "en el área gris entre las categorías, para problematizar la codificación de género y representar un espacio textual liminar" (11). Ese espacio liminar entre la ficción y la no ficción es el de la autoficción. Si continuamos, entonces, con la reflexión sobre la autoficción como género, hemos de tener en cuenta la indefinición y flexibilidad con que la hemos caracterizado, y a ello sumarle que los sujetos narrativos (narradora y autora) de La casa en Mango Street son femeninas y además chicanas. Por ello, encontramos aquí una doble codificación esquinada, marginada cada una bajo diferentes mecanismos opresores que intentaremos explicar. Esta controversia, que nada entre la incomodidad y el humor, se hace posible gracias a la actuación de los mecanismos ficcionalizadores ${ }^{8}$ sobre dos de los pilares fundamentales de la autobiografía y el género diarístico: la privacidad y la testimonialidad. Es de este modo como se potencian sus posibilidades de denuncia y rebeldía.

Como afirma Ana Casas, la autoficción se inscribe de forma clara en las tendencias hacia la fragmentariedad e inestabilidad presentes en el arte contemporáneo, precisamente porque en las obras se debate la moderna noción de "sujeto" como unidad (2011: 13). O incluso, en ocasiones, el autor quiere mostrar al lector el intento por trasladar esa "unidad del sujeto" a la narración para que este desenmascarare, como en un juego de códigos o capas ocultas, el inevitable fracaso al que le conduce esa búsqueda (Casas, 2015: 174). Esta realidad del "desvelamiento" en el texto del carácter precario del sujeto creador es acogida de forma clara por Sandra Cisneros, ya que acentúa doblemente el lugar desde el que, como mujer chicana, ella escribe.

No hay en su obra, pues, un anhelo ni nostalgia hacia la idea de una voz única y verdadera, sino que se apropia de esa sensación de inestabilidad para mostrar problemáticas situadas en

\footnotetext{
7 Podríamos también vincular el género diarístico al "short story cycle", pues cada entrada se sucede como se suceden los pequeños relatos: mediante los recortes de realidad que realiza la voz narrativa.

${ }^{8}$ Entre estos mecanismos se encuentran la ramificación, plurificación y alteridad del yo-mujer.
} 
espacios marginales y que afectan a identidades divergentes, gracias a la voz de la infancia de Esperanza Cordero, una voz casi coral por el carácter heterogéneo de la comunidad que pretende darnos a conocer.

\section{RAÍCES MOVEDIZAS: IDENTIDAD Y LITERATURA CHICANAS}

En las formaciones precapitalistas se encuentran todas las crueldades y terrores, fragmentos de cadena significante están afectados por el secreto, sociedades secretas o grupos de iniciación- pero nunca hay nada inconfesable, propiamente hablando. Es con el capitalismo que empieza lo inconfesable, es decir, su perversión intrínseca o su cinismo esencial.

“El Anti-Edipo. Capitalismo y esquizofrenia", Deleuze y Guattari (1972)

Preguntarse por una determinada literatura es también preguntarse, justamente, por una determinada identidad, que encuentra en la escritura un medio no solo para manifestarse, sino un medio que le permite ir reconociéndose a sí misma a medida que se va construyendo, y lo hace literariamente, porque, como la propia lengua en la que se escribe, no es una cosa fija y estable, sino movediza, cambiante, viva.

Es difícil o imposible hablar de "identidades puras" y lo es aún más hoy, cuando los movimientos migratorios, resultado de crisis y guerras, las huellas del colonialismo y la expansión de mercados nacionales a países extranjeros han provocado no sólo una fuerza globalizadora y un sincretismo brutal, sino la configuración de unas producciones literarias que ya no obedecen exclusivamente a la localización geográfica y la lengua propia. Ahora obedecen a las normas del mercado y las exigencias del canon internacional, cuyo criterio responde más al número de ventas y los intereses comerciales de las editoriales que a componentes exclusivamente literarios o artísticos.

Desde esta perspectiva, hablar de la identidad y literatura chicanas como "mestizas" 9 es afirmar que esta comunidad de mexicanos emigrados a Chicago y, sobre todo, sus posteriores generaciones, se encuentran en un enclave aún más inter-medio $0^{10}$ y fragmentado que otras culturas que nadan hoy en el mar de los medios de comunicación y de Internet. También podríamos añadir a este hecho la presión que el sistema capitalista ejerce sobre las minorías, las diferencias sociales, y en general, sobre todo "yo" que esté fuera de su campo de control.

\footnotetext{
9 Usamos aquí la palabra "mestizas" sabiendo que el término ha perdido, especialmente en las últimas dos décadas, gran parte de su potencial reivindicativo para con las comunidades que han sufrido procesos de aculturación y colonización interna. Sin embargo, el término "mestizo" ha sido muy relevante para comunidades como la chicana, especialmente a finales de los años 80 y 90, como lo demuestran las posturas de Alfred Arteaga en su ensayo Cbicano Poetics. Heterotexts and Hybridities (1997) o Gloria Anzaldúa en Borderlands/La Frontera. The New Mestiza (1987). La teoría del mestizaje (o mestisaje según Anzaldúa) fue un punto de partida para las futuras miradas decoloniales hacia las identidades fronterizas y subalternas. La Casa en Mango Street es ya una manifestación temprana de ese carácter "liminar" de la mujer chicana de clase trabajadora, como también afirma Claire Smith (2016).

10 Spoturno usa este término, citando a Homi K. Bhabha (The Location of Culture: 1994), para referirse principalmente al espacio lingüístico en que se escriben las "literaturas de minorías", que lo hacen en una lengua dominante que no es la suya, otorgándole nuevos sentidos a esa lengua mayoritaria (Spoturno, 2009: 126). Tanto esa idea como la de la desterritorialización, tomada de Guattari y Deleuze (1980), nos serán útiles en este trabajo.
} 
Como contrataque, la literatura se alza como un espacio de configuración de identidad (de ahí las muchas novelas del yo $0^{11}$ chicanas), pero también de cambio social, económico, político y cultural, y desde esta reflexión, no podemos pensarla como una mímesis de su realidad histórica, sino como un consciente híbrido entre la memoria de cada autor y su creación de otras experiencias ficticias (y posibles).

Cabe preguntarse ahora: ¿qué tipo de proceso ha sido el de la construcción de una identidad y cultura propias del pueblo chicano y qué papel ha jugado la literatura en él?

Tomando un poco de perspectiva respecto a la historia política y social del pueblo chicano, lo cierto es que, hasta la llegada del Movimiento en los años 60, el sentimiento de unidad y de identidad colectiva era, al menos, frágil. La "porosidad" en el sistema norteamericano, de la que a continuación hablaremos, permite la existencia de una clase media acomodada entre los mexicano- americanos que ha ido siempre en contra de los intereses de la mayoría chicana, ${ }^{12}$ y esto ha incrementado las dificultades para crear un tejido colectivo de reivindicación y lucha que fuera lo suficientemente fuerte como para generar grandes cambios sociales.

Sin embargo, la unificación y consideración colectiva de una identidad común eran necesarias para que el pueblo chicano se levantase contra el mito del "asimilacionismo" o integración de minorías distintas en la cultura mayoritaria y dominante. Como bien explica el también escritor chicano Rudolfo Anaya: "Assimilation, on the other hand, only raised false hopes for our people, so it was a time of crisis, a time that begged for the "señores of the communal time"13 to once again insist on our right to our values and history" (Anaya, 1989: 233).

Conscientes del fracaso de estas políticas, una gran parte de los chicanos optó por el apropiamiento de su identidad o conformación de una etnogénesis desde procesos muy similares a los de los pueblos indígenas: la reivindicación de un espacio como una tierra en la que vivir emancipadamente tanto en el nivel económico como cultural (Gómez y Hadad, 2007: 6-7). Para ese vuelco colectivo o "territorialización" de y en un espacio, la representación de este en medios de difusión cultural comunes será una condición de vital importancia. Es el caso, por ejemplo, de la literatura chicana.

\footnotetext{
11 Así es como Alberca llama en su monografía El Pacto Ambiguo (2007) a las novelas que parecen autobiografías, pero tienen forma y rasgos propiamente novelescos o ficticios.

12 Puede decirse que los términos "mexicano-americano" y "chicano" son parecidos y a veces se usan como sinónimos (por ejemplo, en Cañero, 2017); sin embargo, mientras que el primero alude a cualquier persona que nace o vive en E.E.U.U. y tiene ascendencia mexicana, el segundo tiene una función social y política mucho más fuerte y está ligado al Movimiento Chicano, que surgió en los años 60 y 70 (Smith, 3). De esta forma, solo emplearemos el término "mexicanoamericano" cuando nos refiramos a tiempos anteriores al Movimiento Chicano o cuando queramos hablar de todo el conjunto de habitantes en E.E.U.U. vinculados por sus raíces a México, pertenecientes o no al Movimiento. En esta cita puede apreciarse esa diferencia, ya que no todos los "mexicano-americanos" consideran que su identidad es "chicana", de hecho, pueden producirse fuertes discrepancias ideológicas, que suelen estar vinculadas a conflictos de identidad de clase.

13 La filosofía del Movimiento estaba basada en el "renacer" de la comunidad chicana mediante la recuperación de elementos indígenas o ancestrales, como la concepción y apropiación de un tiempo específico y distinto, más próximo al mítico que al vivencial por ser no-lineal. Es el llamado "prior time" de los "señores" (puede apreciarse aquí el lugar que la mujer viene arrastrando dentro de la propia cultura chicana).

La "ceremonia del nombre", mediante la cual se bautizan a sí mismos como chicanos (Anaya, 1989: 230-241), nutre a la manifestación de un espíritu nacionalista, aunque Anaya proclame constantemente la búsqueda de un "hogar sin fronteras".
} 
Esa "territorialización" se llevará a cabo a través de la reivindicación de un lugar de origen ancestral, mítico y simbólico — Aztlán, origen de los aztecas- de dudosa localización histórica y científica, que ha marcado un antes y un después en los movimientos chicanos, pues ha sido mediante la búsqueda de ese lugar propio y espiritual que sus posturas han girado durante mucho tiempo en torno al nacionalismo y la independencia, llegando incluso a autoidentificarse como la raza (Anaya, 1989: 231).

Hemos de señalar también que, desde el propio nacimiento del proceso, el espacio que los chicanos han reivindicado para ellos ha estado quizás no en un plano tan imaginario como espiritual, pero sí innegablemente abstracto y simbólico, casi literario, podríamos decir. No es azaroso entonces que Esperanza tenga la necesidad de escribir el hogar con el que sueña: "I like to tell stories. I tell them inside my head" (109). Esperanza escribe y también lo hace su amiga Minerva porque para ellas, y podríamos decir que para los chicanos desde su "renacer", la literatura se abre como un posible crear senda, como un posible enunciar colectivamente. El espacio reivindicado no podía sino estar en el plano de la autoficción —en el primer nivel narrativo, que corresponde a Sandra Cisneros_- y en el que llamaremos de la ficción pura o ensueño - en un segundo nivel, el de Esperanza Cordero-.

De alguna manera, en cambio, se siente que, histórica y políticamente, el Movimiento Chicano no tuvo la repercusión que podría haber alcanzado. De hecho, constituyó, pese a sus triunfos, algunos fracasos, como pudo ser el de la creación de una férrea frontera que, paradójicamente, ha perpetuado las condiciones de vida de las personas chicanas en los barrios, o al propio barrio como gueto.

César A. Gómez y María Gisela Hadad realizan una crítica a las recepciones actuales del concepto de Deleuze y Guattari de "desterritorialización" y una de ellas resulta interesante de traer aquí: estriba en considerar, como única consecuencia de la globalización y el desplazamiento de pueblos respecto a sus culturas y/o tierras de origen, la tendencia a la homogeneización entre ellas. En cambio, la forja de una identidad colectiva, afirman, recurre a la creación de la frontera étnica nosotros-ellos (Gómez y Hadad, 2007: 13), que estuvo en la base de los movimientos chicanos de los años 60 y 70, y que se muestra en varias de las escenas contadas por Esperanza. Ocurre así en la viñeta “Those Who Don't'” (28), en la que claramente ellos no comprenden la realidad de Mango Street, están fuera de ella por sus prejuicios:

Those who don't know any better come into our neighborhood scared. They think we're dangerous. They think we will attack them with shiny knives. They are stupid people who are lost and got here by mistake.

O en "Bums in the Attic" (86-87), donde Esperanza identifica a los propietarios de casas grandes fuera del barrio como "people who live in hills [and] sleep so close to the stars", enfatizando la distancia con el nosotros que está abajo, en contacto con la tierra: "[...] they forget those of us who live too much on earth. They don't look down at all except to be content to live on hills".

Este fragmento es importante, ya que puede ser leído de dos formas distintas que configuran totalmente la interpretación sobre la posición de Esperanza respecto al barrio. Aunque la mayor parte de la crítica ha elogiado la clara demostración (y denuncia) que en la obra 
de Cisneros se hace del patriarcado dentro de los barrios, así como han visto en Esperanza una nueva forma de enarbolar la identidad chicana, existen lecturas, como la de Julio Cañero (1999), que difieren de forma rotunda de estas hipótesis. Para Cañero, Esperanza representa un fracaso para la comunidad chicana, puesto que abandonando el barrio estaría renunciando a su "verdadera” identidad, a sus raíces. Según el crítico, “Those Who Don't” reflejaría el anhelo de Esperanza por vivir en y ser propietaria de una casa típicamente estadounidense, es decir, el del sujeto oprimido que sucumbe a todo un imaginario impuesto sobre la realización del "sueño americano": "But her victory [su liberación de la opresión en el barrio] requires the confrontation between her Mexican heritage and the new possibilities offered by the Anglo world" (Cañero, 102). Desde su perspectiva, la salida del barrio por parte de Esperanza implica ya una elección absoluta de la cultura angloamericana, sin margen de convivencia entre la Esperanza "mexicana" y la "angloamericana". Sin embargo, los dilemas que nos plantean tanto la narradora como la autora contradicen este argumento: desde el principio, ambas subjetividades se nos plantean bifurcadas entre los dos mundos. Además, considerando la obra como una autoficción, resulta muy relevante que Cisneros, quien puede considerarse una proyección futura de Esperanza, siga teniendo en su vida este dilema y en su identidad esta convivencia problemática entre las dos culturas. Es decir, su identidad como mujer chicana rechaza esa asimilación total de la cultura angloamericana, así como la construcción patriarcal de una "esencia" femenina que está fuertemente delimitada por sus funciones sociales en la cultura mexicana que pervive en los barrios chicanos.

Es clave para nuestra interpretación considerar la obra como una autoficción, puesto que el desenlace de la obra, es decir, la salida del barrio por parte de Esperanza no es el final de la identidad mexicana ni latina en ella, sino el principio de su conciencia chicana, especialmente cuando reconoce que volverá "for the ones who cannot out" (110). Toda la obra es en realidad un gran "darse cuenta" de su identidad fronteriza o "liminar"14 entre dos mundos que están representados mediante el límite impuesto del adentro y el afuera del barrio. El valor del texto $L a$ Casa en Mango Street está en considerarlo una prueba del regreso de Esperanza y de Sandra Cisneros al barrio. Además, la propia naturaleza del texto, su materialidad como objeto compuesto de historias, ensamblado de muchas vidas singulares, especialmente de las vidas de las mujeres que viven en el barrio, dignifica su carácter colectivo y coral. Esto viene a contradecir la opinión de Cañero de que Esperanza estaría defendiendo a toda costa su individualidad al abandonar a las "hermanas" del barrio a su suerte, y considerándose a ella misma superior a las mujeres que permanecen en Mango. Nada más lejos, Esperanza no solo respeta a las mujeres del barrio, a sus amigas, a su familia, sino que no las trata con condescendencia. Guardemos estas ideas para los epígrafes posteriores.

Siguiendo ahora con la pregunta sobre la identidad y la literatura chicanas, ¿por qué la literatura de Cisneros y la de la gran mayoría de escritores y escritoras chicanos se aproxima más a

\footnotetext{
${ }_{14}$ Usamos este término en el sentido en que lo usa Claire Smith en su artículo sobre La Casa en Mango Street (2016). Aquí, la obra se entiende como una de las primeras en reconstruir el concepto de mujer chicana, que de forma tan opresora y férrea se había instalado en el imaginario del Movimiento Chicano y en las obras de los escritores chicanos. Como veremos, este término se aproxima a la noción de "borde" de Gloria Anzaldúa (1987). El espacio habitado por la comunidad chicana, y muy especialmente por las mujeres e identidades queer, es referido en el ensayo de Anzaldúa como "borderland" y su cultura como "border culture".
} 
una reconstrucción de su realidad, mediante mecanismos ficcionalizadores, que a un mero reflejo de ella o una mímesis? Esto ocurre en la medida en que los enormes problemas de esa realidad se pueden enfatizar, mostrar e incluso moldear con esa reconstrucción metaficcional, de modo que la autoficción se vuelve un género bien interesante para los escritores chicanos. Asimismo, para comprender esa reconstrucción nos es necesario tener en cuenta los problemas materiales y políticos de la comunidad chicana que laten en la obra.

No nos sorprende, por tanto, que el componente crítico para con la realidad del día a día de la gente chicana en La casa en Mango Street se venga justificando desde las primeras páginas. Con una especie de boceto de su casa actual en Mango, Esperanza nos muestra cómo han sido sus viviendas anteriores:

The house on Mango Street is ours, and we don't have to pay rent to anybody, or share the yard with the people downstairs, or be careful not to make too noise, and there isn't a landlord banging on the ceiling with a broom. But even so, it's not the house we'd thought we'd get (3).

Acostumbrarse a esa imposición del sentir vergüenza ante los demás es realmente frecuente entre las personas del vecindario, ya que sus espacios vitales, sus casas, son un elemento que los identifica socialmente, les dan identidad, y por eso Esperanza tiene buen cuidado de advertirnos que ese no es el espacio que quiere para ella:

There. I had to look to where she pointed -the third floor, the paint peeling, wooden bars Papa had nailed on the windows so we wouldn't fall out. You live there? The way she said it made me feel like nothing [...] I knew then I had to have a house. A real house (5).

Si nos remontamos al Tratado de Guadalupe Hidalgo ${ }^{15}$, firmado en 1848, tal vez no estemos yendo lo suficiente hacia atrás en la historia de la comunidad chicana. Tendríamos que regresar a la colonización de los pueblos precolombinos establecidos en el sur, centro y norte de América, pues fue la semilla de las relaciones de dominación y subordinación (económicas y raciales) que calarán tanto en la sociedad a lo largo de los cinco siglos que siguieron a la Conquista como para sofisticarse en lo que hoy conocemos como neocolonialismo.

Los intentos por dar una explicación más concreta y radical al estado de opresión en que se encuentra esta comunidad, que es la más grande de las no angloamericanas residentes en los Estados Unidos, con sus 34 millones de personas (Cañero, 2017: 11), han coincidido en un término que describe las relaciones sociales allí dadas con una inquietante veracidad: el colonialismo interno. Pero esta situación no es tanto una novedad como una evolución, pues hablamos de colonialismo como un proceso universal en la historia de la humanidad y entendemos que

\footnotetext{
151848 es una fecha que la mayoría de las periodizaciones apuntan como momento de inflexión en la historia de los mexicanos: estos "entregaron" casi la mitad de sus territorios a EEUU, mientras que el país norteamericano "arrancó" esos territorios para sí y desplazó a la gente que habitaba esas tierras (Anaya y Lomelí, 1991: 83).

El Tratado de Guadalupe Hidalgo prometía igualdad ante la ley, respecto al resto de ciudadanos norteamericanos, a los ahora mexicano-americanos, así como garantías para la protección y conservación de sus bienes. En cambio, y como trataremos de justificar en este punto, el documento perdió su credibilidad cuando "los legisladores de la zona interpretaron que el espíritu del Tratado solo concedía plenos derechos a aquellos que, por el color de su piel, pudieran ser incorporados a la sociedad como ciudadanos blancos" (Cañero, 2017: 105).
} 
explotación y subyugación, o dominación y subordinación (Cañero, 2017: 16), se traducen con seguridad en la invasión que un pueblo hace a otro mediante procesos de sometimiento territorial, económico y cultural.

Desde La casa en Mango Street, apreciamos que el factor xenófobo y de discriminación racial basado en prejuicios se constituye como uno de los principales motivos por los que los pueblos de orígenes no angloamericanos se encuentran en un lugar periférico y marginal en la sociedad. Sería, por tanto, una de las fuentes de alimentación primarias para ese estado colonial interno en Estados Unidos.

Sin embargo, como observa Julio Cañero, el racismo no ha sido a lo largo de la historia el principal motivo por el cual un pueblo ha sometido a otro. Por el contrario, fue la conquista del continente americano desde finales del siglo XV lo que cambiaría el paradigma de colonización: a la economía y la cultura como justificaciones imperialistas ahora hemos de sumar el conflicto entre rąas (Cañero, 2017:27).

A partir de ahí, dar un salto cronológico y pensar en los siglos XIX y XX supone hablar de aculturaciones y exterminios de comunidades diferentes a "las propias", supone recuperar argumentos falaces del imperialismo más rancio y oscuro sobre la supuesta inferioridad de determinadas razas, para establecer nuevas estructuras de dominación internacional mediante la conquista económica y militar de territorios y la privatización del espacio político.

Lo que ocurrirá exactamente con las antiguas colonias europeas, exceptuando a Estados Unidos (que adoptará políticas ferozmente expansionistas y neocolonialistas), será que su supuesta "independencia" y "soberanía” internacionales estarán al servicio de las decisiones económicas de los países neoimperialistas. Como dice Kwame Nkrumah, los países neocolonizados están sometidos económica y políticamente a las directrices de las antiguas y nuevas potencias económicas mundiales, mediante sus intervenciones monetarias, mercantiles y militares, pero también a través de la manipulación de los nombramientos de funcionarios políticos (1966: 3-7), que estarían bajo su control. Al mismo tiempo, Nkrumah plantea los países neocolonizadores como sistemas frágiles y contradictorios, pues aparentan permitir a las personas que viven en las neocolonias mejorar sus estándares de vida, mientras que ellos tienen como objetivo "mantener[las] bajos tales estándares" (1966: 7) en su propio beneficio. En este punto, no es muy distinta la situación de los países neocolonizados, como son los países del continente africano que Nkrumah estudia en su ensayo, de la de muchos distritos y barrios marginales dentro de países neoimperialistas, como Estados Unidos. Es decir, los mecanismos de manipulación económica y tergiversación del discurso político son muy similares en los sistemas de neocolonialismo y colonialismo interno.

Para el caso de los barrios latinos, asiáticos o afroamericanos en Estados Unidos ${ }^{16}$, hablamos de la sutileza política con que este país, a nivel internacional e institucional, presume de un "equal access to the resources necessary for collective political action", así como de "an equal

\footnotetext{
16 Armando Gutiérrez y Herbert Hirsch, a quienes Cañero cita en su estudio, también se refieren a este conjunto abigarrado de culturas en situación de colonialismo interno como "subcultures" (1973), las cuales, según ellos, estarían sometidas a una opresión latente y silenciosa que atraviesa todas las capas de la vida en sociedad, incluyendo la de la autoestima y concepción de sí mismos que tienen los individuos pertenecientes a estas subculturas (832).
} 
opportunity to manifest their desires through participation in the systemically defined channels of political action", según Gutiérrez y Hirsch (1973: 831). Mientras tanto, el "gigante" norteamericano, en realidad, burla con mecanismos legales sus propios presupuestos de pluriculturalidad: una de las trampas está precisamente en que, para llegar a ese "equal access", la condición determinante no es otra que el parecido físico con los grupos angloamericanos blancos. Esta estigmatización de los cuerpos no-anglos, no normativos, ha ido generando un deterioro lento y profundo de la autoestima e identidad de las individualidades marginadas, que desde hace décadas han comenzado a auto-oprimirse. La interiorización inconsciente de la ideología racista dominante (Gutiérrez y Hirsch, 831) ha ido provocando un bloqueo paulatino en la reivindicación política de la comunidad chicana, entre otras ya mencionadas.

La asimilación entonces o lo que se llamó melting pot, ambos conceptos muy defendidos por sociólogos norteamericanos durante todo el siglo XX, nos parecen ahora tan ilusos como culpables (por la pasividad y el peligroso estatismo que desprenden). $\mathrm{O}$, si se prefiere, estos términos han quedado ya muy caducos. Tratemos de explicar por qué: la obtención de mejores puestos de trabajo o de una mejor educación no se consigue recuperando las siguientes ideas del siglo XVII: "Here individuals of all nations are melted into a new race of men [préstese especial atención; las mujeres no formamos parte de esa raza sublime], whose labors and posterity will one day cause great changes in the world" (cit. en Cañero, 2017: 26).

Este supuesto melting pot al final se construye sobre una idea de nación plural y unida que es falaz, pues se trata en realidad de un sistema "poroso", aparentemente lleno de oportunidades, donde la asimilación y la integración culturales no bastan para ascender y alcanzar así unas condiciones de vida igualitarias. No bastan tampoco para que esas comunidades-otras, entre las que se encuentra la chicana, sean respetadas en la sociedad en la que viven. Es en esa sociedad donde se incrementa la sensación de no pertenecer a ninguna parte — de estar desplazados-, que puede generarse con el exilio a otro país o con el frecuente rechazo que desprenden los lugares de los que se emigra.

Resulta imprescindible, por lo tanto, hacerse consciente de las relaciones de poder que subyacen a la idea de esta sociedad pluricultural. Por un lado, es una estrategia que se sabe más eficiente y barata para el propio Estado angolamericano, pues ahora no tiene que desplegar su poder militar ni político para atajar revueltas indígenas en sus nuevos territorios incorporados, como afirman Gutiérrez y Hirsch (1977: 833). Al contrario, se ha conseguido que sea dentro de las propias subculturas o comunidades oprimidas desde donde se empieza a perseguir y a borrar sus propios signos de identidad, aquellos que les alejan de lo anglo, y con ello, de una supuesta mejora de las condiciones de vida. Por otro lado, y como hemos mencionado anteriormente, esta estrategia también ha provocado que las comunidades que han querido reivindicar su identidad permanezcan en los espacios en que pueden medianamente conservarla y manifestarla. Sin embargo, estos espacios, como muestra La casa en Mango Street, están privados de agencia tanto política como económica, y terminan afianzándose como guetos en situación de marginalidad y pobreza, en la mayor parte de los casos.

En esta línea, Cañero trae a su ensayo los nueve mecanismos que Barrera, Muñoz y Ornelas (1974: 292-294) proponían para visualizar el silenciamiento político al que fue sometido el pueblo 
chicano. De esos nueve mecanismos, es este el más interesante para nuestro estudio, ya que establece un lazo directo entre ese contexto de dominación vestida de sutileza y la dificultad que en él supone construir una identidad propia:

9. Se manipularon los simbolos de identidad para perpetuar los estereotipos de inferioridad biológica y cultural de las minorías. Por ello [...], los chicanos se vieron forzados a tomar posiciones defensivas contrarias a los intereses de su propia comunidad o a interiorizar esos estereotipos de inferioridad, buscando la aprobación de los anglos en cada toma de decisión (1974: 109).

En su ensayo Ghosts and Voices: Writing from Obsesion (1987), Sandra Cisneros nos confirma este hecho: "as a poor person growing up in a society where the class norm was superimposed on a TV screen, I couldn't understand why our home wasn't all green lawn and white wood like the ones in 'Leave it to Beaver' and 'Father Knows Best”' (Madsen, 2000: 5). Igual lo hace Esperanza cuando juega todas las tardes a ser "somebody everybody knew", imitando a personajes o figuras icónicas de la televisión norteamericana, como Wonder Woman o Marilyn Monroe. Sin embargo, hay que destacar también que, finalmente, recurre a personas cercanas a ellas, como su tía Lupe (59), poniendo al mismo nivel a las personas de su alrededor, del barrio, que a las estrellas de Hollywood.

\section{MÁS ALLÁ DEL BARRIO, MÁS ALLÁ DE MANGO STREET}

Los movimientos chicanos, como hemos visto, han ido basando sus luchas en la reivindicación de un hogar donde ver realizada su personalidad desde lugares simbólicos de culturas ancestrales, como es Aztlán. Este espacio "espiritual" donde construir una nación no está tan pensado sobre fronteras políticas, sino sobre la reconstrucción de unos lazos culturales e históricos entre las personas chicanas y la tierra que les fue arrebatada ${ }^{17}$. Además, con ella, les fueron arrebatados sus derechos humanos y civiles.

El espacio reivindicado mediante el lenguaje no podía sino estar, pues, en el plano de la autoficción: más allá de los barrios en los que les ha tocado permanecer con la reorganización de las ciudades, o a los que han tenido que desplazarse para sobrevivir. Esperanza nos cuenta que su padre se levanta cansado cuando aún es de noche, en "Papa Who Wakes Up Tired in the Dark"; entendemos que probablemente trabaja más horas de las establecidas legalmente. También somos conscientes de ello cuando nos habla de Rosa Vargas, en "There Was an Old Woman She Had So Many Children She Didn't Know What to Do"; todo el trabajo que debe hacer para que ella y sus "too many and too much" hijos (29), que además se lo ponen muy difícil, consigan seguir adelante sin el marido-padre que los ha abandonado a su suerte. Esperanza, por su parte, debe trabajar con sus doce años para seguir estudiando en una escuela católica porque la escuela pública es demasiado peligrosa, tal y como lo cuenta en "The First Job”.

Mango Street es sin duda un barrio marginal y por ello los padres de Cathy "Queen of Cats" se van a vivir a otro lugar pensado por ellos como "más seguro". El tratamiento jerárquico, de menosprecio y elitismo, que Cathy muestra hacia a Esperanza y el resto de los vecinos del

${ }^{17}$ Así como sus propios cuerpos, que habían sido "utilizados para la guerra” (Plan Espiritual de Aztlán, 1989: 4). 
barrio es solo una manifestación de la capacidad de aprendizaje de los niños para reproducir las estructuras de poder en que han sido educados en casa.

Pero es precisamente esa separación residencial la que estrecha la complicidad y afectividad entre los vecinos de Mango Street, la que acerca a Esperanza a cada una de las personas que ocupan un espacio fundamental sobre las páginas que ella va escribiendo.

Ese más allá arriba mencionado, Homi Bhabha lo estudia no como un lugar concreto ni definido por etiquetas o categorías cerradas, sino caracterizado por el movimiento constante entre los límites impuestos por las relaciones de poder que consolidan una sociedad. Nos referimos a los límites entre "pasado y presente", "adentro y afuera", "inclusión y exclusión", "diferencia e identidad" (Bhabha, 2013: 17). Ese movimiento — su naturaleza del una y otra vezparece hendir de alguna manera entre esas fronteras culturales, espaciales y temporales hasta generar un lugarls horizontal e intersticial o inter-medio donde crear una subjetividad en su colectivo: el del sujeto subalterno.

Tengamos ahora en cuenta dos importantes hechos:

- Para la mayoría chicana, uno de esos bordes se sitúa exactamente entre su tradición cultural (su lengua y costumbres) y los hábitos de la cultura angloamericana que les fueron impuestos si querían integrarse y mejorar sus condiciones de vida, a través de esta relación de causaconsecuencia también impuesta ( $\mathrm{y}$ falaz).

- El barrio, aunque se convierte, como hemos visto, en "algo parecido" a un hogar, con la protección que puede generar el sentirse parte de una comunidad donde todo el mundo vive en condiciones de marginalidad, no lo es tanto para la mujer. Al contrario, este enclaustramiento y opresión que sufren las mujeres dentro y fuera de los barrios chicanos es algo que Esperanza y Sandra Cisneros enfatizan una y otra vez en La casa en Mango Street ${ }^{19}$.

\footnotetext{
18 En concordancia con la propuesta de Bhabha para considerarlo un lugar permeable y dinámico, Arteaga habla de mestizaje e hibridez identitarias y, en paralelo, también textuales: "The place where the mestizo body resides is algo conceived ambiguously because of its own sort of hybridity" (Arteaga, 1997: 11), para afirmar después que "Chicano speech is like the mestizo body and the borderlands home: it simultaneously reflects multiple forces at play and asserts its hybridity" (1997: 16).

${ }^{19}$ Esta situación de desarraigo y violencia que coloca a las mujeres de la obra en un lugar identitario fronterizo es también manifestada de una forma brillante y esclarecedora en la película estadounidense The Florida Project (2017), dirigida por Sean Baker. Ambas piezas, texto literario y filme, manifiestan llamativas analogías, pues están contadas por dos niñas que habitan espacios muy periféricos (un barrio marginal de Chicago y un motel de paso a las afueras del parque temático de Disney World, en Florida, donde conviven distintas comunidades, como la afroamericana y chicana, entre otras).

Las dos miradas muestran el proceso en el cual conviven la ingenuidad de la infancia (con elementos como la imaginación, el juego o la curiosidad característicos de ambas niñas) con su propio quiebre.

Podemos afirmar, para ir más allá, que ambas obras representan formas novedosas de contar las problemáticas específicas a las que se enfrentan las niñas que nacen en Estados Unidos en condiciones de pobreza y marginalidad:

la sexualización del cuerpo desde la infancia, la normalización del consumo de drogas, el racismo, los abusos, la prostitución como último recurso o la maternidad no deseada son algunas de ellas. A esto hemos de añadir una estética caracterizada por frecuentes contrastes y giros humorísticos que consiguen descolocarnos. Así, mientras que a nivel discursivo se nos cuenta la situación de pobreza y violencia en que se encuentran las comunidades mostradas, a nivel visual el constante movimiento y juego de las dos niñas tienen lugar en espacios muy coloridos, casi mágicos ("Mango Street" y "The Magic Castle" son los nombres de los lugares en que viven las dos niñas), produciendo una fuerte sensación de ironía en el receptor. Esta ironía, que Cañero no parece percibir en su lectura de la obra de Cisneros (1999), enfatiza la violencia y la pobreza sin idealizarlas ni espectacularizarlas. Al contrario, produce una fuerte sensación agridulce que se empaña de tristeza y rabia.
} 
Si al hombre chicano se le impide desarrollar y afirmar su identidad como mestizo por cuestiones económicas, étnicas y raciales, la mujer chicana, además de encontrarse en esa misma situación, ve negada la realización de su identidad como mujer fuera pero también dentro del barrio. La tradición mexicana para con los estereotipos de género es rígida y se reproduce tanto desde los hombres hacia las mujeres como entre ellas (Candelaria, 1993: 22-23). Cuando Esperanza nos cuenta que, como su abuela, nace en el año chino del caballo, nos dice:

She was a horse woman too, born like me in the Chinese year of the horse-which is supposed to be bad if you're born female-but I think this is a Chinese lie because the Chinese, like the Mexicans, don't like their women strong (10).

Esta mención de la comunidad china no es azarosa, como tampoco lo es la atención dirigida a la puertorriqueña en varias viñetas. Vale la pena recuperar la observación de la poeta, ensayista y activista chicana Gloria Anzaldúa acerca del carácter heterogéneo que posee el espacio que ella llama indistintamente "borderland" o "la frontera" (1987: 11). Esta tierra, cercada por un "alambre" afilado, en nuestro presente cada vez menos metafórico, que punza y duele 20 mantiene la herida abierta de la colonización, la diáspora y el expolio de la "homeland" entre sus habitantes. Aquellos atravesados viven en el inestable y movedizo espacio intersticial de la frontera entre dos (o más) culturas: la latina, entre la que destacan la chicana y la nuyorriqueña, la negra o afroamericana y la asiática (especialmente la china), anotando solamente las que son referidas con más atención en La casa en Mango Street. Esto nos ofrece también la idea de que los barrios no suelen "pertenecer" a subculturas que se encuentran aisladas unas de otras: por el contrario, y especialmente en el caso de las comunidades latinas, suelen convivir, o al menos colindar, entre ellas, aunque de forma problemática en muchos casos. En la siguiente descripción, extraída de "Those Who Don't", Esperanza especifica que hay vecindarios de otros colores ${ }^{21}$ con los que "los de piel marrón" mantienen una relación conflictiva, y no parece referirse aquí solamente a los barrios de supremacistas blancos:

All brown all around, we are safe. But watch us drive into a neighborhood of another color and our knees go shakity-shake and our car windows get rolled up tight and our eyes look straight. Yeah. That is how it goes and goes (28).

Por otra parte, y volviendo a la distancia entre hombres y mujeres en el barrio, Esperanza también es absolutamente consciente de que "boys and girls live in separate worlds" desde la propia experiencia que vive con sus hermanos, quienes fuera de la casa cumplen esa especie de rol al "autoprohibirse" hablar con chicas (8).

En este sentido, lo que vemos es que la "autoficción diarística" (Mesa Gancedo 146) que podría constituir la obra se convierte en un lugar donde ocurre, en tiempo real o en el "tiempo de vida" (ib.), la construcción de una identidad femenina. Como en otros textos vinculados al diario

\footnotetext{
20 "This thin edge of barbwire", dice Anzaldúa (3).

${ }^{21}$ Una hipálage que nos indica cuál es el elemento por el que se identifican espacios como los barrios que colindan a las afueras de las grandes ciudades norteamericanas.
} 
desde la ficción y escritos por mujeres latinoamericanas ${ }^{22}$, la niña que narra su día a día en La casa en Mango Street es consciente de la anormalidad que supone experimentar algunos sucesos (de violencia tanto física como discursiva) a su edad ${ }^{23}$.

De esta manera, su libreta o diario no es solamente un espacio donde volcar sus sentimientos o guardar secretos íntimos (la que sería la clásica visión del diario, asociado a su vez a la "escritura femenina"), sino un espacio donde cuestionar las relaciones de poder impuestas y donde afirmar los cuidados entre las mujeres del barrio: como afirma Mesa Gancedo, la ficción en el diario parte, pues, de "motivaciones políticas" (148).

Por tanto, ¿qué hay de Marin, de Rosa Vargas, de Alicia, Rachel, Ruthie, Mamacita, Rafaela, Sally, Minerva, la madre de Esperanza, Esperanza y todas aquellas niñas, adolescentes, mujeres que son forzadas a recibir y aprender todo tipo de violencias patriarcales — sumisión, maltrato, estereotipos - dentro de una comunidad que está internamente colonizada?

Para intentar trazar la posición en que se encuentra la mujer chicana desde su condición de subalternidad en el barrio, intentamos poner en diálogo este concepto de lugar "inter-medio" de Homi Bhabha (1994) con el de wild zone que Edwin y Shirley Ardener proponen (1977) y que conocemos mediante Cordelia Chávez Candelaria (Candelaria, 1993: 21-31). Vemos que este punto de encuentro entre ambas teorías se aprecia en las reflexiones que Esperanza Cordero nos ofrece en su narración y los retratos que en ella hace de las mujeres que viven en Mango Street.

En párrafos anteriores destacábamos el espacio como una posible senda en la que reivindicar una identidad colectiva; ahora, simultáneamente, hemos de pensar las tensiones que para una mujer supone la búsqueda de ese más allá desde el centro de un sistema ultrapatriarcal. Nos encontramos, pues, con un movimiento paradójico que oscila entre la aceptación de las normas sociales de dominación masculina (ejercida y perpetuada también por ellas mismas) y la búsqueda de la realización de su personalidad como mujeres sin las imposiciones de la tradición mexicana ni del patriarcado a un nivel global.

En Mango Street, esas tensiones están muy presentes: en primer lugar, porque no todas las mujeres buscan una alternativa a su situación (pensemos en Ruthie, que vive con su madre pese a haberse casado, o en Sally, que termina regresando a casa con su padre, aunque este la maltrata, y todo el mundo lo sabe). También lo sabemos por las propias dudas de Esperanza: ¿cómo saber si una quiere gustar a los chicos porque es su deseo o si eso es lo que se espera de una? ¿ Ser libre para salir de casa, estudiar, quedar con chicos? ¿O no está una más bien alejándose de las tradiciones y costumbres del barrio,

\footnotetext{
22 En su estudio sobre la obra Todos se van (2006), de la cubana Wendy Guerra, Mesa Gancedo inscribe el texto en una reciente tradición de obras escritas por mujeres de habla hispana, comenzada en el último cambio de siglo, que amplía la forma de escritura de ficción diarística a "autoficción diarística". Esta nueva forma enfatizaría sus posibilidades de reapropiación, desde la subversión, de algunos territorios de la "intimidad", como el de las relaciones afectivas tanto en sociedad como en el núcleo familiar, asociados a "lo femenino" y al género del diario por igual (2014: 145-159). La casa en Mango Street coincide en numerosos temas y formas con las obras propuestas por Gancedo, por lo que no solo resulta interesante inscribirla en esta genealogía de autoficciones diarísticas transatlánticas escritas por mujeres, sino que puede considerarse una obra pionera, dada la fecha de su primera publicación en la edición en inglés (1984).

23 Recordemos que, aunque la voz narrativa "recorta" y "expone" caprichosamente los sucesos que quiere contar, existe una progresividad en el relato. De hecho, se trata de la narración de una vida en secuencias, aunque el motivo del recorte de cada secuencia no sea tanto el día o momento exacto, sino el espacio en que se desarrolla cada una de ellas.
} 
asumidas y/o heredadas de nuestras madres, y acercándose a la cultura de ellos, los que nos desprecian, los que nos marginan?24

La wild zone constituye un espacio "fractural" y separado de las hegemonías del barrio, pero es por esas hegemonías que indaga sobre sí misma para autodefinirse.

Resolver la paradoja es difícil para Esperanza, para Sandra Cisneros y para el resto de nosotras, pues una quiere salir de ese edificio férreo y hostil que nos han construido e impuesto, un espacio de violencia y sumisión, pero, al mismo tiempo, el espacio perseguido no está fuera de la sociedad, sino dentro; está dentro y fuera simultáneamente, en un constante movimiento de "adelante y hacia atrás", o si se prefiere, de ida y vuelta. La idea de una "esencia" de lo femenino no tiene ya tanto sentido si es en contraposición con lo socialmente establecido — que es lo patriarcal y con ello, los roles de género impuestos-. Pero es precisamente por eso que las mujeres buscamos realizarnos más allá de los discursos dominantes para volver a ellos y así nosotras hacer que exploten desde dentro con todo lo prístino y "wild" que ello necesite.

Frente a la crítica que ha visto en Esperanza Cordero un ejemplo de abandono egocéntrico o individualista de su propia comunidad, de sus raíces, como es el caso de Cañero (1999), aquí vemos en ella lo que Gloria Anzaldúa llamó un movimiento de rebeldía hacia una cultura cuyas normas habían sido escritas y delimitadas por "machos" (17). Por eso, "the culture expects women to show greater acceptance of, and commitment to, the value system than men" (17). Para Cañero, Esperanza traiciona la "esencia" de su identidad chicana que estaría completamente recogida en la cultura del barrio. Sin embargo, como explican y defienden Anzaldúa, Cisneros y la propia Esperanza, es su cultura la que las traiciona. La identidad de las mujeres chicanas no puede encontrarse completamente en el barrio, puesto que la propia cultura del barrio limita su identidad a tres cosas: hacerse monjas, prostituirse o permanecer en el espacio doméstico como madres (Anzaldúa, 1987: 17). La identidad de la new mestiza, de la nueva mujer chicana, entonces, está más allá del barrio, en él y fuera de él, aunque su cultura criminalice y condene a aquellas que se atreven a salir, aunque las tache de "traidoras", "hociconas" o "burras" (Anzaldúa, 1987: 15, 17, 21). Respondemos a ese señalamiento que hace Cañero de Esperanza como traidora hacia su cultura con las palabras de Anzaldúa, que bien podrían ser las de Cisneros en su prólogo o las de Esperanza en los últimos episodios de La casa en Mango Street.

Not me sold out my people but they me. So yes, though "home" permeates every sinew and cartilage in my body, I too am afraid of going home. Though I'll defend my race and culture when they are attacked by non-mexicanos, conosco el malestar de mi cultura. I abhor some of my culture ways, how it cripples its women, como burras, our strengths used against us, lowly burras bearing humility with dignity [...]. No, I do not buy all the myths of the tribe into which I was born [...]. And if going home is denied me then I will have to stand and claim my space, making a new culture — una cultura mestiza - with my own lumber, my own bricks and mortar and my own feminist architecture (21-22).

\section{UN JUEGO UN POCO SERIO: POÉTICAS AUTOFICCIONALES EN LA CASA EN MANGO STREET}

\footnotetext{
${ }^{24}$ Estas cuestiones no están explícitamente en palabras de Esperanza, pero nos permitimos suponerlas a partir de la lectura, señalándolas por ello en cursiva.
} 
Monee- You know why this is my favorite tree?

Jancey- Why?

Monee- 'Cause it's tipped over, and it's still growing

“The Florida Project" (2017)

Hemos analizado a lo largo de este artículo cómo la búsqueda de la realización de la identidad chicana (femenina) está vinculada a la reivindicación de un lugar, de un espacio singular y concreto. También hemos establecido un vínculo entre esa lucha y las posibilidades que la literatura le proporciona. Desde esta perspectiva, el tiempo no se cobra la fuerza crítica y persuasiva que sí adquiere el espacio a lo largo de toda la obra.

Partiendo de esta idea, cabe señalar también que, en el caso de La casa en Mango Street, la autoficción no se sustenta casi exclusivamente en su carácter autorreflexivo, es decir, poniendo el énfasis en la narración en vez de en lo narrado —así es la definición que Toro propone del género (Toro, 2017: 141)—. Por el contrario, siguiendo los estudios de Mario de la Torre ${ }^{25}$, la autoficción se manifiesta como un medio de persuasión y de protesta, siempre con la mirada puesta en los acontecimientos narrados y la posibilidad que estos tienen de referenciar la realidad para cambiarla.

La narración, que busca la horizontalidad sin perder por ello dinamismo, se embriaga de protesta contra una realidad social que es vertical ${ }^{26}$ porque es jerárquica. Para conseguirlo, Esperanza hará que su narración gire no tanto en torno a sí misma, sino sobre el universo de Mango Street. Pero no con detalles, no con descripciones extensas, ni mediante la reproducción fiel de diálogos entre personajes. Lo conseguirá a través de la brevedad, frases como ráfagas, y el lirismo, como si se encontrase en un carrusel que gira sobre sí mismo y desde el cual tenemos pinceladas de las personas del barrio y de los lugares en que viven.

Esta construcción de un relato que acentúa su carácter dinámico sin apoyar por ello la narración en el factor temporal, como sí hacen las autobiografías, lo vemos también en las constantes referencias al movimiento y al juego:

Down, down Mango Street we go. Rachel, Lucy, me. Our new bicycle. Laughing the crooked ride back (16).

And Uncle spins me, and my skinny arms bend the way he taught me, and my mother watches, and my little cousins watch, and the boy who is my cousin by first communion watches, and everyone says, wow, who are those two who dance like in the movies, until I forget that I am wearing only ordinary shoes, brown and white, the kind my mother buys each year for school (47).

\footnotetext{
25 Para ver la conferencia en línea, consúltese la bibliografía.

${ }^{26}$ Son frecuentes las reflexiones implícitas de Esperanza sobre lo chicano como lo bajo, lo que está en el suelo. Las casas en las colinas, el cielo o la fuerza de los árboles, en cambio, se presentan, como en una jerarquía, en un nivel superior. Recordemos que en el episodio "Meme Ortiz" Meme se parte ambos brazos subiéndose a los árboles.

También, para un análisis exhaustivo sobre la casa como espacio vital e identitario en la obra, en contraste con La poética del espacio de Bachelard (1957), véase el ensayo de Julián Olivares "Sandra Cisneros: The House on Mango Street and The Poetics of Space" (1996).
} 
Ficción y espacio se enfatizan para buscar la complicidad y la empatía del lector. La narración gira en torno a Mango Street y las personas que viven en él para protestar, para colocar en el centro una identidad femenina en vaivén. No claramente definida. Quizá nunca definible.

Por todo ello, si el espacio en que se localiza la identidad chicana es intersticial, permeable y dinámico, y en él, el de la mujer — esa zona de búsqueda desde la contradicción— es aún más profundo y escurridizo, el discurso con que se van a enunciar esos movimientos de ida y vuelta no puede sino identificarse por su predisposición a la indefinición, "burlando" las categorizaciones-frontera de géneros literarios. Su naturaleza es paradójica. Pensemos en La casa en Mango Street: la autora coloca "A House of My Own" como prólogo (como paratexto, por tanto, junto con la breve presentación de sí misma y los títulos de la obra y de las viñetas) y lo hace para que establezcamos puentes que sitúen a Esperanza y al resto de personajes entre la realidad biográfica-testimonial y la ficción. Sandra Cisneros, además, dedica el texto preliminar a su madre, Elvira Cordero, cuyas iniciales y apellido coinciden con los de la madre de Esperanza ${ }^{27}$.

En cambio, al mismo tiempo, desde este prólogo se acentúa el carácter ficcional de la obra gracias a la enunciación de Cisneros de sí misma en tercera persona, a partir de una fotografía suya en la que aparece más joven. De esta manera nos parece que se va a ir introduciendo en el plano de la ficción, más como personaje que como autora, y es su voluntad que nosotros entremos con ella. El juego y la paradoja están desde la cubierta del libro, pues como afirma Ana Casas: "la autoficción llama al referente para negarlo de inmediato" (Toro, 2017: 139).

Por su parte, y como trazando una línea contraria a la de la autora en ese prólogo, Esperanza pondrá de manifiesto en algunos momentos su consciencia de que está narrando, y es por ello que a veces apela nuestra atención con un "you know" (29) o "see. That's what I mean" (30). Nos tutea casi todo el tiempo en un tono que oscila entre lo oral, lo cotidiano y lo cómico: "I sit on the back seat and Rachel is skinny enough to get up on the handlebars which makes the bike all wobbly as if the wheels are spaghetti, but after a bit you get used to it" (15-16). La sensación que se genera de este cruce narrativo es la del intercambio del papel de autoría.

Hemos de señalar, sin embargo, que Esperanza también tiende a dejar inconclusas ciertas ejemplificaciones mediante frecuentes aposiopesis, que a nuestro modo de ver constituyen

\footnotetext{
${ }^{27}$ Según Ana Casas, en el texto autoficcional se establecerían dos códigos que aproximarían al receptor a una lectura o bien en clave autobiográfica o bien en clave de ficción. Sin embargo, también el texto demanda una interpretación que se sitúe entre esa doble codificación, no teniendo que elegir uno u otro acercamiento, sino participando en ese lugar intermedio, en la creación de soluciones a las incógnitas que plantea la figuración del yo-que-escribe. De no entrar en este juego, Casas reconoce que "la lectura se vería empobrecida", ya que "la exigencia posmoderna de un receptor precavido y suspicaz también parece ser una de las condiciones de la autoficción a tener en cuenta" (2015: 177- 178).

Desde esta perspectiva, Cisneros "ayudaría" al lector, desde su prólogo, a identificar el uso de mecanismos metaficcionales, así como esos momentos dentro de la narración en los que la consciencia de la autora sale a la luz. Cisneros también relata en el prólogo que para escribir la obra no solo se nutrió de los propios recuerdos de su infancia, sino que quiso ensamblar estos recuerdos a algunas de las experiencias de la vida en el barrio que sus alumnos le contaban. Lo que está haciendo Cisneros es mostrar la naturaleza del texto como retablo de voces, un artefacto que se propone hacer crítica social y política desde la "desarmonía" entre el discurso literal y sus otros significados; en definitiva, desde la ironía. Resulta también interesante que Casas señale la ironía como uno de los elementos clave en la autoficción hispánica, tanto en la Península como al otro lado del Atlántico (2015), y que Cisneros suela recurrir a esta estrategia discursiva para describir aquello que más caracteriza a la protagonista como "hispana" (uno de los elementos identitarios que la hace víctima de distintos tipos de opresión).
} 
momentos en los que no solo la Esperanza del tiempo futuro, sino también la propia escritora Cisneros se dejan ver en la narración. Son momentos, por tanto, antilusorios en su fuerte carácter insinuador, sugerente e irónico, que hacen tambalear la inestable ilusión referencial de la obra:

Our laughter for example. Not the shy ice cream bell's giggle of Rachel and Lucy's family, but all of a sudden and surprised like a pile of dishes breaking. And other things I can't explain.

[Marin] is the one who told us [...] what cream is best for taking moustache hair and if you count the white flecks on your fingernails you can know how many boys are thinking of you and lots of other things I can't remember now (27).

Esperanza desarticula su propio hilo narrativo, pues ¿cómo si no dedica fragmentos enteros a describir metafóricamente un olor o una risa y sin embargo en otras ocasiones termina abruptamente los episodios porque no sabe cómo decir o no recuerda?

Sabemos que Sandra Cisneros "wants to write stories that ignore borders between genres, between written and spoken, between highbrow literature and children's nursery rhymes, between New York and the imaginary village of Macondo, between the U.S and Mexico" (Cisneros, 2009: xvi-xvii). Observamos que, en paralelo, Esperanza hace elásticas las paredes de la prosa testimonial y biográfica, acercando así su discurso a un lirismo que se detiene en descripciones metafóricas verdaderamente sorpresivas, usando para ello casi permanentes tiempos verbales en presente:

Then he stars it up and all sorts of things start happening. It's like all of a sudden he let go a million moths all over the dusty furniture and swan-neck shadows and in our bones. It's like drops of water. Or like marimbas only with a funny little plucked sound to it like if you were running your fingers across the teeth of metal comb (20).

En esta escena en que Nenny y Esperanza van a curiosear a la tienda de compraventa de Gil, los sonidos que la caja de música produce contrastan fuertemente con su vieja y fea apariencia, tal y como ella nos la describe. La música, que tiene un papel crucial en toda la obra, se alza aquí como símbolo de la memoria y de las emociones ${ }^{28}$ mediante la narración metafórica y plagada de sinestesias de Esperanza. Pero, además de ello, consideramos que la música es un mecanismo recurrente en la obra para generar lo que se ha llamado mise en abyme, y que Toro califica como una estrategia paradójica de fuerte énfasis metaficcional (Toro, 2017: 215-219).

La caja, además, tiene algo mágico que evoca en Gil recuerdos de una tierra perdida, de una identidad localizada en un más allá. Esa magia evocadora y la búsqueda de la identidad mediante un espacio propio estará también en la escena en que Elenita, que lee las cartas a la gente para adivinar su futuro, ve en Esperanza "a new house, a house made of heart" (64). O con las comadres o "The Three Sisters". De nuevo en esta viñeta, entre lo mágico y lo cómico subrayando ambos factores el estatus ficcional o de cierto aire de ensoñación en la narración episódica de Esperanza-, se le da a nuestra protagonista un consejo clave para nuestra interpretación de la obra de Cisneros: "When you leave you must remember always to come back

\footnotetext{
28 Descubrimos, después, el valor que la caja tiene para Gil, pues no la pone en venta, un gesto que desafía la lógica apropiacionista del mercado en el sistema capitalista.
} 
for the others. A circle, understand? You will always be Esperanza. You will always be Mango Street. You can't erase what you know. You can't forget who you are" (105).

Volviendo a la música, la presencia de las canciones que las chicas aprenden desde niñas en el barrio atraviesa la estética de toda la obra, con su estilo oral y rítmico. "Red Clowns" es quizá la viñeta en que la narración alcanza un mayor clímax de violencia. Es también la más musical de todas; casi podemos escuchar, al leerla, la letra de una canción:

I like to be with you, Sally. You're my friend. But that big boy, where did he take you? I waited such a long time. I waited by the red clowns, just like you said, but you never came, you never came for me (99-100).

Las frases cortas y musicales, casi epifonemáticas, contrastan con la brutalidad del contenido: Esperanza no solo nos está describiendo que un desconocido ha abusado sexualmente de ella ${ }^{29}$, sino que está mostrándolo para nosotros, mediante el contraste entre las apelaciones a su amiga Sally en presente y el uso de tiempos verbales en pasado. Consigue que la línea que separa la realidad presente del recuerdo se difumine:

Sally Sally a hundred times. Why didn't you hear me when I call? Why didn't you tell them to leave me alone? The one who grabbed me by the arm, he wouldn't let me go. He said I love you, Spanish girl, I love you, and pressed his sour mouth to mine (100).

Sally, make him stop. I couldn't make them go away. I couldn't do anything but cry. I don't remember. I don't remember. Please don't make me tell it all (100).

De nuevo, la aposiopesis: no sabemos exactamente qué ha ocurrido, si Esperanza, además de sufrir abusos, ha sido violada. No tenemos toda la información, pero es precisamente en las lagunas donde el relato se vuelve más lírico: "Only his dirty fingernails against my skin, only his sour smell again. The moon that watched. The tilt-a-whirl. The red clowns langhing their thick-tongue laugh" (100).

Por otra parte, es solo en "Hips" donde se explicitan las canciones, y constituyen por sí mismas una suerte de pasadizos o de códigos — mise en abyme - que ayudan a comprender el episodio; dan un mayor nivel de significación a la historia contada y abren nuevas vías de interpretación, que es lo que Cisneros persigue con fuerza en su propia poética (Cisneros, 2009: xvii).

Rimas fáciles e infantiles como las siguientes contrastan afiladamente con lo que cualquier chica o chico cantaría a esa edad. Ellas cantan, pero nosotros las recibimos de lleno en la conciencia:

"Skip, skip, / snake in your hips. / Wiggle around / and break your lip"

"The waitress with the big fat hips/ who pays the rent with taxi tips/says nobody in town will kiss her on the lips/because.../ because she looks like Christopher Columbus" 30 (51).

\footnotetext{
${ }^{29}$ De esta narración deducimos que este desconocido no pertenece al barrio, que es, probablemente, un angloamericano, pues él llama a Esperanza “Spanish girl”: “He wouldn’t let me go. He said I love you, I love you Spanish girl' (100).

${ }^{30}$ Las palabras en negrita han sido resaltadas por la autora de este artículo.
} 
"My mother and your mother were washing clothes. / My mother punched your mother right in the nose. /

What color blood came out?" (52)

Las dos primeras estrofas, inventadas por las hermanas Rachel y Lucy, aunque parece al principio que no tienen ningún tipo de connotación más que su carácter lúdico e infantil, dan un giro al final que nos descoloca. Aluden ambas a dos cuestiones transversales en la obra que aquí hemos apuntado: la violencia en y desde el espacio que las mujeres ocupan en el barrio, y la colonización como un hecho actual y presente en el día a día de los chicanos.

La tercera de las estrofas la canta la más pequeña, Nenny, aunque no la inventa ella. Nenny simplemente la ha aprendido y la repite, pero es tan brutal su contenido y significación y tan ejemplificadora de la aprehensión de la violencia, el machismo y el racismo desde niñas también desde niños-, que nos confirma que la música va más allá de la ficción en La casa en Mango Street.

Así pues, este fuerte carácter metaficcional presente en la obra nos permite alinearnos con la postura de Vera Toro y afirmar que la autoficción se alza precisamente como un género distinto de la autobiografía. Hemos estudiado las condiciones en las que Cisneros está escribiendo esta obra compuesta de viñetas o "short stories", unas condiciones de marginalidad y colonialismo interno que van en dos direcciones interrelacionadas: es chicana y es mujer. Ambos hechos permiten establecer un diálogo precisamente porque para verse realizados necesitan de un lugar, de un espacio donde ser. Sin embargo, no siempre la reivindicación del espacio se ha hecho de la misma manera dentro de la comunidad chicana, ni la mujer tiene en los barrios una posición que le permita ver realizada su identidad (tanto dentro como fuera de ellos).

El resultado de esta opresión hacia la mujer chicana, que se palpa en las viñetas narradas por Esperanza Cordero, será la búsqueda del desarrollo de la subjetividad en un espacio intersticial no definido entre el barrio y la ciudad, entre los roles de género femeninos y los masculinos, entre la cultura mexicana heredada y la cultura angloamericana en la que hoy los chicanos como Esperanza han nacido.

Dos conceptos fundamentales nos permiten arrojar luz sobre esa búsqueda. El primero es el de lugar cultural intermedio, propuesto por Homi K. Bhabha para hablar de comunidades en subalternidad, como es la chicana en Estados Unidos; en segundo lugar, el de wild zone, que desarrollan Edwin y Shirley Ardener y que sitúa a la mujer en un espacio en movimiento entre la violencia impuesta por la cultura patriarcal y la lucha por comprender la especificidad en la diferencia indentitaria de las mujeres. Ambos dialogan entre sí, así como con la teoría/poética de la frontera/borderland de la chicana Gloria Anzaldúa, una teoría que ampara a subjetividades anuladas u oprimidas por su propia cultura, como es el caso de las mujeres en el barrio chicano, y que comprende y explica el movimiento de rebeldía que se desarrolla en algunas de estas mujeres hacia su tradición.

En cualquier caso, ese vaivén espacial y simbólico se manifiesta en el texto mediante un estilo breve y lírico, imbuido de metáforas y sinestesias, en un juego constante con la ficción, la ilusión referencial y sus frecuentes rupturas a través de mecanismos antilusorios y 
metaficcionales, como la mise en abyme en las canciones, las aposiopesis y su constante estética musical y epifonemática.

Si en la autobiografía la narración prosaica y regresiva están al servicio del desarrollo de una vida en el tiempo, en la autoficción de La casa en Mango Street Esperanza nos cuenta su vida en los espacios, nos la cuenta desde un carrusel donde el humor y la ternura no impiden un discurso de rabia, de protesta. 


\section{BIBLIOGRAFÍA}

AlBerCA, Manuel (2007). El pacto ambiguo. De la novela autobiográfica a la autoficción. Madrid: Biblioteca Nueva.

AnAya, Rudolfo, LOMELÍ, Francisco A (1991). Aztlan: Essays on the Chicano Homeland. Alburquerque: University of New Mexico Press.

ANZALDÚA, Gloria (1987). Borderlands/La Frontera. The New Mestiza. San Francisco: Aunt Lute Book.

ARTEAgA, Alfred (1997). Chicano Poetics. Heterotexts and Hybridities. New York: Cambridge University Press.

BACHELARD, Gaston (1993). La poética del espacio. Madrid: Fondo de Cultura Económica.

BAKer, Sean (2017). The Florida Project. Estados Unidos: Cre Film / Freestyle Picture Company / June Pictures.

BARTHES, Roland (1987). El susurro del lenguaje. Más allá de la palabra y de la escritura. Barcelona: Paidós.

BHABHA, Homi K (2013). El lugar de la cultura. Buenos Aires: Manantial.

CASAS, Ana (2014). "La autoficción en los estudios hispánicos: perspectivas actuales". Casas, Ana (ed.). El yo fabulado. Nuevas aproximaciones críticas a la autoficción. Frankfurt: Iberoamericana: $7-21$.

CASAS, Ana (2015). "Desmontando al autor: ironía, parodia y sátira en la narrativa y el cine autoficcionales". Tropelías. Revista de Teoría de la Literatura y Literatura Comparada 24 (2015): 174-190.

CAÑERO, Julio (2017). Literatura Chicana. La experiencia colonial interna en las obras de Rudolfo Anaya. Madrid: Instituto Franklin UAH.

CAÑERO, Julio. “Esperanza's transcendence: sense of community in Cisneros' The House on Mango Street'. REDEN: Revista española de Estudios Norteamericanos 17-18 (1999): 101-112.

Chávez Candelaria, Cordelia (1993). "The "Wild Zone" Thesis as Gloss in Chicana Literary Study". Alarcon, Norma, Castro, Rafaela, Pérez, Emma, Pesquera, Beatriz, Sosa Riddell, Adaljiza, Zavella, Patricia (eds.). Chicana critical issues. Oakland and Saline: Third Woman Press: 21-33.

Cisneros, Sandra (1984). The House on Mango Street. New York: Vintage Books.

Cisneros, Sandra (1994). La Casa en Mango Street. New York: Vintage Español.

DE LA TORRE, Mario (2017). La autoficción como método de protesta: prácticas teatrales y cinematográficas en el ámbito bipánico.

Deleuze, Gilles, Guattari, Félix (2014). El Anti-Edipo. Capitalismo y esquizofrenia. Barcelona: Paidós. 
Deleuze, Gilles, GuATTARi, Félix (2004). Mil mesetas. Valencia: Pre-Textos.

FOuCAult, Michel (2003). “¿Qué es un Autor?”. Repositorio Institucional de la Universidad de los Andes.

GutiÉRREZ, Armando y HiRSCH, Herbert. "The militant challenge to the american ethos: "Chicanos" and "Mexican Americans"”. Social Science Quarterly 53 (1973): 830-845.

HADAD, Gisela, GÓMEZ, César (2007). “Territorio e identidad. Reflexiones sobre la construcción de territorialidad en los movimientos sociales latinoamericanos". Acta Académica.

L. MADSEN, Deborah (2000). Underestanding contemporary Chicana literature. Columbia: University of South California Press.

Mesa GANCEDO, Daniel. "La imagen del yo en la novela-diario femenina del siglo XXI: Todos se van, de Wendy Guerra”. Mitologías hoy 10 (2014): 145-15.

Nkrumah, Kwame (1966). Neocolonialismo. Última etapa del imperialismo. México D.F: Siglo XXI Editores.

Olivares, Julián. "Sandra Cisneros: The House on Mango Street and The Poetics of Space". The Americas Review 15 (1987): 160-170.

SMiTH, Claire. "La reescritura de la imagen chicana desde los espacios liminares de The House on Mango Street'. La BloGoteca de Babel. 6 (2016): 1-31.

SPOTURnO, María Laura. "Las paremias como puentes interculturales en Caramelo de la autora chicana Sandra Cisneros". Paremia (2009) 18: 121-130.

TORO, Vera (2017). Soy simultáneo. El concepto poetológico de autoficción en la narrativa hispánica. Madrid: Iberoamericana. 